\title{
La nahda como despertar político en el Magreb: tensiones históricas y conceptuales en el pensamiento de Mālik Bennabī
}

\author{
The nahda as a political awakening in the Maghreb: historical and \\ conceptual tensions in Mālik Bennabī’s thought
}

\author{
Juan A. MACÍAS AMORETTI \\ Universidad de Granada \\ jamacias@ugr.es
}

Recibido: octubre 2012

Aceptado: marzo 2013

\section{RESUMEN}

La figura del pensador argelino Mālik Bennabī (1905-1973) es sin duda una de las más importantes e influyentes del pensamiento magrebí y árabe contemporáneo. Partiendo de una lectura salafí y nacionalista, el islam es considerado por Bennabī como una herramienta de liberación cultural y política de los pueblos colonizados del Tercer Mundo. Su conceptuación ideológica procede de la salafiyya, por una parte, y del pensamiento nacionalista europeo, por otra, y es analizada en el presente artículo a partir del concepto de "nahḍa", el cual constituye uno de los vértices metodológicos y conceptuales de su pensamiento político. Dicho concepto, además, pone en relación el pensamiento político anticolonialista árabe con la realidad sociopolítica de los países árabes en la actualidad.

Palabras clave: pensamiento político, colonialismo, Mālik Bennabī, Magreb, Argelia.

\begin{abstract}
The Algerian thinker Mālik Bennabī (1905-1973) is one of the most important and influent figures of Contemporary Maghrebi and Arab thought. Starting from a wide salafi and nationalistic view, Islam is considered by Bennabī as a cultural and political liberation tool in the colonized areas of the Third World. His ideological conceptualization comes from the salafiyya, as well as from the European nationalistic thought, and in this article it is analysed through the concept of "nahḍa", which is one of the methodological and conceptual keywords in his political thought. This concept links also the anticolonialist Arab political thought to the socio-political facts in the nowadays Arab countries.
\end{abstract}

Keywords: Political Thought, Colonialism, Mālik Bennabī, Maghreb, Algeria.

SUMARIO: 1. Introducción: Mālik Bennabī (1905-1973) y el concepto de "nahụa", 2. Nahḍa y hadāta en el contexto cultural y político colonial magrebí, 3. La dimensión histórico-política de la nahda: colonialismo y autoconciencia, a) Linealidad vs. carácter cíclico de la historia: tensiones metodológicas, b) El fenómeno islámico como elemento político anticolonial, 4. La nahḍ y el despertar político afro-asiático, 5. Conclusión. 


\section{INTRODUCCIÓN: MĀLIK BENNABĪ (1905-1973) Y EL CONCEPTO DE "NAHḌ"}

El concepto de "nahḍa" suele ser entendido y estudiado como un término fundamentalmente literario y más ampliamente cultural. Es cierto que este concepto surge en el ámbito literario para expresar el "resurgimiento" o "renacimiento" de la cultura, las letras y la lengua árabe particularmente a partir de mediados del siglo XIX en la zona sirolibanesa, aunque no es menos cierto que el amplio movimiento cultural emprendido por los primeros autores e intelectuales árabes conlleva un proceso social y político más amplio que engloba a los pensadores de la época, que harán suyo en concepto de "nahḍa" aplicado al ámbito del pensamiento en general, particularmente con un interés activo propio de la filosofía de la acción y, por tanto, resueltamente ético-moral y político ${ }^{1}$.

En el mismo sentido, otros muchos pensadores posteriores son influidos por este pensamiento de la nahda como "resurgimiento", lo que, de manera general, es aplicado en un contexto colonial caracterizado por las fuertes luchas sociales y políticas por las independencias árabes a principios y mediados del siglo XX. El Magreb, cuyo traumático proceso colonial es especialmente grave por lo que tiene de aculturación y destrucción identitaria en aras de los valores superiores del sistema moral exógeno, léase francés, el concepto de la nahda viene principalmente importado desde el Mašreq por los primeros pensadores salafies y nacionalistas y, por tanto, con un fuerte contenido religioso y modernizador, siendo después reapropiado y asumido por los propios pensadores magrebíes, muchos de los cuales viajan constantemente o estudian en países como Siria, Líbano o Egipto. Ellos, no sin fricciones en algunos casos, lo adaptan a su propia personalidad cultural e identitaria, por otra parte fuertemente marcada, y lo contextualizan en el marco de la lucha política por la independencia, dotándolo de un marco de referencia netamente nacionalista y de una vocación discursiva políticamente activa ${ }^{2}$.

Este es el caso del pensador argelino Mālik Bennabi ${ }^{3}$, nacido en la ciudad de Constantina en 1905 en el seno de una familia tradicional y religiosa ${ }^{4}$. Como ejemplo de los nuevos intelectuales y pensadores que forjarán el tejido ideológico e intelectual de las independencias, Bennabī crece en el contexto de la colonización

${ }^{1}$ Cfr. PACHECO, Juan Antonio. El pensamiento árabe contemporáneo: rupturas, dilemas, esperanzas. Sevilla: Mergablum, 1999.

${ }^{2}$ Cfr. MACÍAS AMORETTI, Juan A. y MARSÁ FUENTES, Juan. "The struggle for reform: contested conceptualizations of ișlāh in the Maghreb". The Muslim World 102 (2012), 211-224.

${ }^{3}$ Dependiendo del sistema de trascripción, y teniendo en cuenta las particularidades lingüísticas del Magreb, el nombre del autor aparece generalmente en su versión francesa como Malek Bennabi. En árabe puede encontrarse como Mālik Ibn Nabī, Mālik Bin Nabī o Mālik Binnabī. Siguiendo la convención más generalizada y por motivos funcionales, en el presente trabajo se ha optado por la versión intermedia Mālik Bennabī.

${ }^{4}$ TARĀBĪSĪ, Ŷūrŷ (ed.). Mu 'ŷam al-falāsifa. S.v. “Ibn Nabī, Mālik”. Beirut: Dar al-ṭal̄‘a, 1987, 32-33. 
francesa, por lo que recibe una educación coránica tradicional a la vez que estudia en un liceo francés, formándose en los valores de la modernidad europea, y posteriormente en Francia, donde adquiere un título en ingeniería eléctrica. Sin embargo, en los años 40 y 50, Bennabī se decanta plenamente por la labor intelectual y educativa a través de la publicación de ensayos y de algún que otro texto literario enfocado a analizar las condiciones del islam y los musulmanes en la convulsa época en que le ha tocado vivir. En este sentido, es de especial relevancia la obra que publica en 1948 bajo el título de Šurūt al-nahd $a^{5}$, originariamente en francés como Les Conditions de la Renaissance ${ }^{6}$. Es esta sin duda una de sus obras clave, siendo fundamental para entender toda su obra posterior y para observar el desarrollo precisamente del concepto de "nahḍa", que él traduce al francés como renaissance (renacimiento), vinculando sin duda a nivel ideológico el proceso emancipador de los musulmanes con el renacimiento europeo del siglo XVI. Aunque en esta época se centra en aspectos relacionados con la cultura y la religión, en la década de los 50 su evolución le lleva a adoptar decididamente una marcada postura política a favor de la lucha independentista en Argelia y a desarrollar, especialmente en sus obras S.O.S al-Ŷazā'ir (1957) y al-Afrü-asiyāwiyya (1960), un pensamiento internacionalista y comprometido políticamente con el movimiento de los no-alineados y contra el colonialismo.

Tras la independencia de Argelia en 1962, Bennabī es nombrado director de Educación Superior en 1964, aunque renuncia años después, en 1967, para dedicarse exclusivamente a la escritura y a la labor de conferenciante, dada su creciente fama en el mundo árabe, especialmente en el dinámico mundo cultural y político de finales de los años 60 en el oriente árabe.

Fruto de la propia trayectoria biográfica de Mālik Bennabī, que culmina con su muerte en 1973, y de sus relaciones tejidas con el propio proceso histórico árabe y argelino en la época de las luchas nacionales, particularmente en Argelia, su pensamiento aborda cuestiones profundas que pretenden situar al ser árabe y argelino en el mundo y en la historia, lo cual sin duda constituye el armazón principal de la labor filosófica, siendo consciente de la trascendencia de dicha labor en un momento tan crucial como difícil de la historia árabe y magrebí. Es por ello que su teoría filosófica, que aborda cuestiones fundamentales de la filosofía política y de la cultura, está determinada por la referencia a una serie de conceptos clave

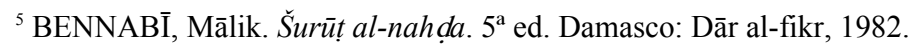

${ }^{6} \mathrm{El}$ hecho de que Bennabī decidiera escribir en francés como primera lengua revela de manera evidente hasta qué punto la política de aculturación llevada a cabo por la colonización francesa fue efectiva en Argelia, donde incluso un pensamiento marcadamente nacionalista y salafí como el de Bennabi se veía abocado a utilizar dicha lengua para expresar sus ideas anticoloniales. Posteriormente, como elección ideológica, el propio Bennabī decidirá traducir sus obras al árabe e, incluso, comenzar a escribir en dicha lengua, como se verá. BENNABI, Malek. Les conditions de la Renaissance Algerienne. Le Problème d'une Civilisation. Argel: Les Editions Algeriennes En-Nahda, 1949. 
que la estructuran y le dan un sentido global. Entre ellos, cabe destacar el análisis de la fenomenología islámica, el desarrollo del proceso social, y la cultura y la política como marco de desarrollo de las sociedades humanas. Sin duda, la aproximación al concepto de "nahḍa" en el pensamiento de Bennabī supone uno de los elementos más destacados y valiosos de su aportación al pensamiento árabe, de la que luego se harán eco otros pensadores árabes y magrebíes que profundizarán en este mismo concepto, del que aquí destacaremos sus aspectos más marcadamente políticos.

\section{NAHDA Y HADĀTA EN EL CONTEXTO CULTURAL Y POLÍTICO COLONIAL MAGREBÍ}

La nahda, como concepto cultural, antes de entrar en su contenido político, es entendida desde su puesta en marcha como un método propio de alcanzar la modernidad en todos los niveles. En primer lugar, supone el acceso de los árabes a la expresión de la modernidad en su propia lengua, pues desde mediados del siglo XIX la colonización y la puesta en marcha de mecanismos de ocultación o backlash ${ }^{7}$ por parte de las políticas coloniales habían dado como resultado una profunda alienación lingüística y cultural y una identificación necesaria e inmediata entre la modernidad como concepto y la lengua/cultura del colonizador, fundamentalmente inglés o francés. Es decir, la nahda hace que los árabes asuman, por vez primera en la época contemporánea, que se puede ser moderno y hablar, escribir, leer y pensar en lengua árabe, para lo cual someten a la propia lengua árabe fuṣhà a un complejo proceso de simplificación, estandarización y difusión, como es conocido. Sin embargo, la nahda va mucho más allá, suponiendo un auténtico modo de situarse ante la modernidad por parte de los árabes, y constituyendo uno de los conceptos básicos para desarrollar posteriormente cualquier marco teórico destinado a alcanzar la modernidad de forma integral, o bien a diseñar una modernidad propia, para salir de la crisis producida por los largos años, o siglos, de colonización y de sumisión a las ideas y los planes de los colonizadores.

Por tanto, no puede siquiera hacerse mención a la idea de la nahda sin tener en cuenta su relación dialéctica y necesaria con el concepto de hadāta (modernidad) que la condicionó desde su nacimiento y la sigue condicionando aún en la actualidad. A partir de esta idea, y planteándola en un marco socio-histórico de desarrollo, es necesario mencionar, al menos, dos líneas principales de pensamiento presentes entre los intelectuales y pensadores árabes desde mediados del siglo XIX,

${ }^{7}$ Cfr. MACÍAS AMORETTI, Juan A. "Democracia y backlash neocolonialista en el pensamiento político árabe contemporáneo: perspectivas ideológicas y socio-históricas”. En Jesús Abellán Muñoz, Alfonso Cortés González et alii (eds.). La praxis de la paz y los derechos humanos. Joaquín Herrera Flores In memoriam. Granada: Universidad de Granada: 2012, 353-373. 
cada una de las cuales representa un determinado camino epistemológico y conceptual diferenciado que condiciona las herramientas intelectuales, metodológicas $\mathrm{y}$, sobre todo, los fines mismos del proceso de "resurgimiento" y "modernización" en el ámbito árabe contemporáneo y que, de manera evidente, lo sigue condicionando en la actualidad:

a) La primera de estas líneas bebe de forma inmediata de las fuentes filosóficas europeas del siglo XIX, y más concretamente del pensamiento ilustrado y liberal. Por ello, en ella se concibe la nahda árabe como un proceso de modernización (tahdi $\bar{t} \underline{t}$ ) y de desarrollo irreversible hacia una sociedad mejor. Por influencia del pensamiento liberal europeo, la concepción de esta sociedad se dibuja en un plano temporal lineal y no cíclico, como era tradicionalmente concebida la historia en el pensamiento árabe e islámico clásico, en el que el futuro a construir condiciona inevitablemente el presente en todos los planos. La ciencia y la tecnología serían herramientas principales de este progreso de iluminación y desarrollo que, por sí mismo, conseguiría acabar con la situación de atraso y crisis de los árabes, que debían romper con todos aquellos elementos presentes en su tradición cultural y religiosa que lastrase el objetivo del progreso. En un principio, el horizonte ideal a construir se dibujaba en las mentes de los liberales árabes como una recreación de la Europa de las luces, por lo que entre las herramientas metodológicas que utilizaron figura de manera destacada el derecho. Gran parte de la burguesía árabe liberal vio en la implantación de constituciones y códigos de derecho europeo tras las independencias -más o menos formales- de sus países, el culmen de sus aspiraciones, bien que éstas terminaron derivando en el fracasado modelo de la tecnocracia de la que habla el pensador marroquí 'Abd Allāh Larwī y la burocratización anquilosadora de los estados árabes post-independientes y sus élites políticas que, hasta hoy día, han venido elaborando un discurso liberal plagado de referencias a la democracia, el desarrollo y la reforma como recurso de legitimidad, siendo un discurso carente por completo de significado social real, mientras que colonizaban "interiormente" el país y sus recursos económicos, tal y como apunta Burhān Gāliyūn";

b) La segunda línea de pensamiento en la que se inscribe el concepto de "nahḍa" la constituye lo que podría denominarse de manera más o menos

\footnotetext{
${ }^{8}$ LAROUI, Abdallah. La crise des intellectuels arabes: traditionalisme ou historicisme? París: Maspero, 1974.

${ }^{9}$ Cfr. GĀLIYŪN, Burhān. Bayān min aŷl al-dīmuqrātiyyya. $5^{\text {a }}$ ed. Casablanca/Beirut: Al-Markaz al-taqāfî l-'arabī, 2006, 7, donde el autor desarrolla el concepto del "colonialismo interior" (al-isti 'mār al-dājilī como uno de los colonialismos, junto con el colonialismo exterior, que impiden el desarrollo de auténticas democracias en los países árabes.
} 
amplia, la tendencia salafí. Esta segunda línea, sin embargo no es necesariamente, al menos no en todos los casos, una línea de pensamiento exclusivamente religiosa. Más bien supone una mirada introspectiva y revivificadora a la propia tradición cultural, religiosa e histórica árabe e islámica, ilustrada por los conceptos de "salaf" o de "turāten", y que, a través de diversas ideologías y metodologías, pretende construir una modernidad basada en presupuestos endógenos. Esta línea de pensamiento, fundamental para entender la filosofía árabe contemporánea desde el personalismo musulmán al neo-jaldunismo, así como el desarrollo de las principales ideologías políticas del mundo árabe contemporáneo desde el nacionalismo árabe al islam político, no se propone tratar de alcanzar una modernidad al estilo europeo, sin que eso signifique que en todos los casos se reniegue de las aportaciones de occidente en muchos campos, no sólo en el científico y tecnológico, sino también en el político y en el filosófico, del que toma muchos elementos metodológicos y conceptuales, sino que pretende reunir los elementos necesarios para tratar de construir y alcanzar un modelo de modernidad propio, verdaderamente emancipador, congruente y respetuoso con los valores, la historia y el legado cultural y filosófico árabe e islámico. En esta línea de pensamiento, la nahda es concebida como el "resurgimiento" árabe e islámico a partir de una recuperación de la autoconciencia del "yo" árabe o, mejor dicho, del "nosotros", pues los autores y tendencias de esta línea plantean sus proyectos en clave de desarrollo social $\mathrm{y}$, por tanto, colectivo, en aras de la mencionada modernidad.

Esta segunda línea define el marco de desarrollo del pensamiento de muchos y diversos filósofos y pensadores árabes contemporáneos. Entre ellos, Mālik Bennabī, quien experimenta vitalmente la dinámica del pensamiento y la acción en una época convulsa, considerando necesaria e indispensable la reflexión sobre ese "nosotros" mencionado que, en una primera etapa, se identifica en su pensamiento con los musulmanes de Argelia, por lo que el islam y el análisis racional de sus fuentes se constituye en primer y principal objeto de su reflexión y de sus estudios más profundos; en cierta forma, Bennabī, de formación occidentalizada y moderna, no concibe la modernidad sin el islam, como tampoco puede concebir un islam antimoderno, pues, al contrario del pensamiento materialista, Bennabī no considera que religión y modernidad sean antagonistas, sino que sitúa el conflicto entre dos aproximaciones filosóficas diferentes, a saber, el materialismo y la espiritualidad ${ }^{10}$. Posteriormente, ya en una etapa más política, la nahda se erige para él como elemento dinamizador de la sociedad árabe e islámica y, por tanto, como un camino

${ }^{10}$ EL-TAHRIR EL-MESAWI, Mohamed. "Religión, Society, and Culture in Malik Bennabi's Thought”, en Ibrahim M. Abu-Rabi“ (ed.). The Blackwell Companion to Contemporary Islamic Thought. Oxford: Blackwell, 2006, 219. 
de liberación, desarrollo y modernización social y política de las mismas. De la misma forma, cabe afirmar que las líneas mencionadas no son exclusivas ni estancas, por lo que, como se verá en el caso de Bennabī, ciertos elementos de la modernización occidental, especialmente en el campo metodológico, serán también asumidas por pensadores nacionalistas y salafíes.

\section{LA DIMENSIÓN HISTÓRICO-POLÍTICA DE LA NAHḌA: COLONIALISMO Y AUTOCONCIENCIA}

\section{A) LINEALIDAD VS. CARÁCTER CÍCLICO DE LA HISTORIA: TENSIONES METODOLÓGICAS}

Desde una óptica eminentemente salafí ${ }^{11}$, en el sentido mencionado, Mālik Bennabī aborda el concepto de "nahḍa" situándolo como vértice de su pensamiento social y político, además de cultural. El análisis conceptual que desarrolla, parte de la Historia como marco fundamental de referencia para tratar de desentrañar posteriormente, como se verá, el concepto jalduniano del "eterno retorno" (al- 'idda al-dá 'ima $)^{12}$. La historia, como parámetro temporal, se ve complementada con el parámetro espacio-cultural que Bennabī identifica con el concepto de "civilización", en el cual se inscribe en su análisis el mundo árabe e islámico y más concretamente Argelia, siempre desde una visión humanista y, por tanto, universal:

El drama de cada pueblo es esencialmente el de su civilización. El pueblo argelino no podrá ni comprender ni aún menos resolver su problema en cuanto que no haya elevado su concepción al nivel del drama humano universal. ${ }^{13}$

La "elevación" es sinónimo del "despertar" en la teoría política de Bennabī, lo cual remite claramente al concepto de "nahḍa". Evidentemente, la teoría política de la modernidad salafí tiene una importancia fundamental en la utilización que hace Bennabī de este concepto, tanto desde la dimensión conceptual como desde la concepción lineal-moderna de la historia. Como es habitual en el pensamiento político árabe contemporáneo, la modernidad metodológica de este desarrollo ideológico se presenta en forma de ruptura/continuidad, donde se manifiesta de una manera evidente dicha adscripción salafí de Bennabī: en el contexto histórico de la Argelia pre-independiente, considera importante reafirmar la ruptura definitiva con

${ }^{11}$ Bennabī deja meridianamente clara desde el principio de Les Conditions de la Renaissance su adscripción a los principios de la salafiyya wataniyya argelina, como muestra el hecho de que dedique la obra a la memoria del šayj Ibn Bādis (1889-1940). BENNABI, Malek. Les conditions de la Renaissance..., s.p.

${ }^{12}$ BENNABĪ, Mālik. Šurūtal-nahḍ ..., 20.

${ }^{13}$ BENNABI, Malek. Les conditions de la Renaissance..., 13 ; cfr. BENNABĪ, Mālik. Šurūt al$n a h d ̣ \ldots . ., 22$. La traducción española de las citas, tanto del árabe como del francés, son del autor del presente artículo. 
los modelos ideológicos exógenos e impuestos tales como el "kemalismo, el wahabismo, el europeísmo o el materialismo" ${ }^{14}$ como única salida intelectual a la situación de subyugación del pueblo argelino en particular y el árabe-musulmán en general, optando a su vez por una ruptura que parte de la noción salafí de "reforma" $(i s ̣ l a ̄ h)^{15}$ tomada de la inculturación de dicho concepto realizada, entre otros, por el jeque Ibn Badīs $^{16}$. La ruptura y la reforma son, por tanto, fruto de la historia y no consecuencia de una reflexión aislada del parámetro espacio-temporal. En la Argelia pre-independiente, dicho parámetro se relaciona íntimamente con la colonización, que supone el gran "otro" que permite definir el propio ser. Así, en palabras de Bennabī:

La colonización no es un capricho político, aunque pudiera parecerlo, sino una necesidad de la historia. No se deja de estar colonizado sino dejando de ser colonizable: es una ley inmutable. ${ }^{17}$

Por tanto, la historia enmarca un pensamiento crítico que debe abordar la cuestión fundamental del propio ser, de la identidad del "yo" como sujeto colectivo, cuestión ésta que se sitúa como uno de los grandes ejes del pensamiento árabe contemporáneo y que puede ser encontrada de manera recurrente y fundamental en todos los pensadores árabes y magrebíes desde finales del siglo XIX hasta la actualidad $^{18}$. La solución que en esta línea aporta Bennabī no deja de ser, en cierto sentido, una solución metafísica, dado que para él sólo la transformación del propio ser, del "yo/nosotros", puede ser la clave definitiva para dejar de ser sujetos colonizables y, por tanto, superar históricamente el proceso colonial como sujetos conscientes y libres. La metafísica está presente asimismo en la dicotomía conceptual que enfrenta en su teoría política ese yo consciente y libre frente al "ídolo" (șanam) que representa la mentalidad "tradicionalista e ignorante" 19

${ }^{14}$ BENNABI, Malek. Les conditions de la Renaissance..., 17.

${ }^{15}$ MACÍAS AMORETTI, Juan A. y MARSÁ FUENTES, Juan. "The struggle for reform...”, 211-212.

${ }^{16}$ Sobre Ibn Bādīs y su ideología política, cfr. KAḤḤĀLA, 'U.R. Mu 'ŷam al-mu'allifìn. Tarāŷìm mușannafi l-kutub al-'arabiyya. Damasco: Al-Taraqqī, 1957-1961, vol. V, 105 y MERAD, Ali. Ibn Badis, commentateur du Coran. París: Paul Geuthner, 1971; sobre su papel político a través de la Asociación de Ulemas Argelinos, cfr. PÉREZ BELTRÁN, Carmelo. "La asociación de los ulemas musulmanes argelinos (1931-1954) y la cuestión de la mujer". En Homenaje al profesor José María Fórneas Besteiro. Granada: Universidad de Granada, 1994, vol. II, 813-820.

${ }^{17}$ BENNABI, Malek. Les conditions de la Renaissance..., 22.

${ }^{18}$ Es interesante notar la influencia del pensamiento de Bennabī y particularmente de su concepto de « nahḍa » como renacimiento cultural y político, en otros pensadores magrebíes. Este es el caso del marroquí Muḥammad 'Ābid al-Ŷabrī (1935-2010), cuyo «al-mašrū' al-nahḍwī l- 'arabī» (proyecto de resurgimiento árabe) comparte muchos elementos con la conceptuación cultural, histórica y política de Bennabī. Cfr. 'ĀBID AL-ŶABRĪ, Muḥammad. Al-Mašrū' al-nahḍwī l-'arabī. Murāŷa 'a naqdiyya. $2^{\mathrm{a}}$ ed. Beirut: Markaz dirāsāt al-waḥda al-'arabiyya, 2000.

${ }^{19}$ BENNABĪ, Mālik. Šurūtal-nahḍ..., 68. 
Es necesario en este sentido abordar la teoría de la historia desarrollada en el pensamiento de Bennabī, que, bien que afirma la linealidad del tiempo, en su sentido moderno, al abordar nociones como las de "destino", "liberación", "resurgimiento" o "despertar", es concebida al mismo tiempo como un retorno cíclico y eterno siguiendo el modelo jalduniano. Dicha aparente incoherencia es pretendidamente superada por Bennabī al utilizar la noción del retorno cíclico referida a la evolución cultural y civilizadora de un determinado pueblo:

La historia tiene retornos cíclicos que sitúan el problema de un pueblo, según si se encuentra en un punto u otro de su evolución. ${ }^{20}$

Se trata, según la conceptuación del autor, de "ciclos de civilización" (dā'irat al-ḥad̄arāt), los cuales se desarrollan, dentro de la linealidad del tiempo, a lo largo de tres etapas ${ }^{21}$ :

a) Rūh (alma)

b) 'Aql (razón)

c) Garīza (instinto primitivo)

Conforme a este esquema, una determinada civilización se desarrolla en diferentes etapas a las que acompaña un determinado progreso cultural. El paso de la primera etapa a la segunda constituiría el culmen de su desarrollo, mientras que la tercera sería el periodo de decadencia previo a la desaparición y sustitución de dicha civilización por otra en un estado de desarrollo previo. En el ámbito político, Bennabī utiliza un concepto concreto, el de tawȳ̄h (orientación), para abordar la problemática de la decadencia de la civilización árabe y aportar una solución pragmática para lograr que alcance el ansiado despertar, sólo posible en la etapa de la razón ('aql). Dicho concepto hace referencia a una acción concreta que, partiendo desde las élites árabes y musulmanas, fundamentalmente, "oriente" a la civilización árabe para lograr alcanzar y permanecer el en culmen de su civilización mediante una llamada constante a la "fuerza del origen, la armonía de la marcha y la unidad del objetivo" El elemento pragmático de dicha orientación, la sitúa en tres ámbitos fundamentales: la orientación de la cultura, la orientación del trabajo y la orientación del capital.

La nahda, en este sentido histórico a la vez que netamente político, sitúa el marco de la lucha anti-colonial en una doble perspectiva: por una parte, aquella por la que se observa el pasado, abarcando "todos los sustratos y ramificaciones de la decadencia" y, por otra, aquella por la que es posible observar "las semillas y las raíces del porvenir" ${ }^{23}$. La "orientación" (tawŷ̄̄h) debe ser cultural en primer

\footnotetext{
${ }^{20}$ BENNABI, Malek. Les conditions de la Renaissance..., 30.

${ }^{21}$ BENNABĪ, Mālik. Šurūtal-nahda ..., 66.

${ }^{22}$ BENNABI, Malek. Les conditions de la Renaissance..., 46.

${ }^{23} \mathrm{Op}$. cit, 48.
} 
término -éste y no otro es el sentido radical y fundamental de la nahda-, pero sus consecuencias son, deben ser, de hecho, clara e inevitablemente políticas. La concepción política y social de esta nahḍa tiene asimismo relación con el campo de la ética y de la estética que, desde el punto de vista de la filosofía fenomenológica de Bennabī, completan y dotan de su sentido pleno al proceso de búsqueda de la propia identidad y de liberación del colonialismo.

La orientación ético-moral (al-tawŷ̄h al-ajlāq $\bar{l})^{24}$, como expresión de los valores sociales del islam, entendido desde un análisis teológico salafí, y la orientación estética (al-tawŷ̀h al-yamālī $)^{25}$ como expresión de lo bello, inciden en la recuperación de la propia identidad argelina y musulmana en todos los ámbitos, en contraposición con la del "otro" colonizador, que carece de valores éticos y de belleza espiritual. Así, la estética está íntimamente ligada con la ética y su consecuencia última es el desarrollo de la civilización en todos los ámbitos:

[La estética] es la cara de un país en el mundo. Es preciso salvar nuestro rostro

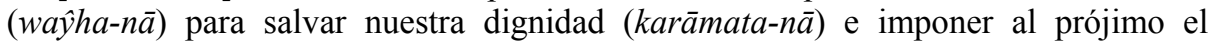
respeto que nos debemos a nosotros mismos. ${ }^{26}$

Además de emprender un proceso de "reforma" integral de la cultura que "oriente" las dimensiones éticas y estéticas del propio yo colectivo, también deben emprenderse, según Bennabī, otras reformas con un claro alcance político destinadas a "orientar" el ámbito del trabajo y del capital en aras al futuro marco de emancipación. Principalmente, ambas reformas suponen actuar en la Historia y, por tanto, convertirse en sujeto político y social activo. A lo largo de su obra, no obstante, Bennabī evita entrar en pormenorizaciones excesivas, por lo que ni en al ámbito económico, ni en el político ni en el social encontramos un plan concreto de desarrollo para una Argelia independiente. En todos ellos, Bennabī trata de evitar apriorismos que pudieran dogmatizar en exceso la puesta en práctica del proceso emancipatorio. Así, tanto los objetivos económicos como los sociales, donde dedica un extenso apartado a la emancipación de la mujer o incluso a la forma de vestir en general, afirman la necesidad de proceder paso a paso diseñando las estrategias teniendo en cuenta los acontecimientos y las circunstancias económicas, históricas, éticas, etc. Lo fundamental para él es la toma de conciencia del pueblo árabe y musulmán entendido como una nación moderna que, como tal, está dotada de los elementos fundamentales que conforman cualquier proyecto nacional de emancipación: población, territorio e historia (pasada y sobre todo futura). La toma de conciencia, en la que estos elementos constitutivos juegan un papel principal, está encaminada al proceso de reforma (iṣlāh) y resurgimiento (nahḍ):

\footnotetext{
${ }^{24}$ BENNABĪ, Mālik. Šurūṭ al-nahḍa..., 88.

${ }^{25}$ Op. cit, 91 .

${ }^{26} \mathrm{Op}$. cit, 99 .
} 
Cuando un pueblo dispone de estas tres cosas [humanidad (al-insān), territorio (alturāb) y tiempo (al-waqt)] y toma conciencia despertándose, tiene en sus manos la llave de su destino. Todavía puede tropezar, puede echar en falta la comodidad y las posibilidades dependientes de las condiciones sociales aún precarias, pero no puede decaer más (...). ¡Es irremediablemente la aurora! ${ }^{27}$

Esta dialéctica entre el proceso cíclico de las civilizaciones y la linealidad de la historia tiene en el proceso de toma de conciencia y de liberación un punto culminante y aparentemente sin retorno. Es, por tanto, en el ámbito político donde se expresa la realidad histórica en toda su complejidad, y es a partir de ella como Bennabī elabora su pensamiento, y no al contrario. Al mismo tiempo, Bennabī inserta su pensamiento entre la particularidad histórica y política del caso argelino y la universalidad de la humanidad en el contexto de la liberación nacional de un gran número de países del denominado "tercer mundo":

El hombre civilizado es un colonizador. El hombre a civilizar es automáticamente un colonizado: un producto colonial que se ha llamado indígena. No hay hombre civilizador, ese es el drama. El hombre civilizado acusa al "otro" de llevar sobre su civilización un juicio de ingratitud y falta de respeto. Más grave aún: imputa la razón de esta "pérdida de prestigio" a un debilitamiento de su potencia material. ${ }^{28}$

Por tanto, el drama histórico es en último término un drama político, en el que tanto colonizador como colonizado son culpables de mantener un statu quo insostenible, cuya única salida es la toma de conciencia y la reflexión. Observada la cuestión argelina desde un prisma de universalidad, las particularidades se difuminan en beneficio de la toma de conciencia, paso indispensable del proceso de resurgimiento (nahda) y verdadero axioma transversal del pensamiento político de Bennabī:

De cualquier forma, logrando su propio renacimiento (nahda) y encaminándose ella misma hacia el progreso moral y científico, será como Argelia podrá contribuir eficazmente a la edificación de la ciudad humana. ${ }^{29}$

Referencia filosófica fundamental que inscribe nuevamente sus ideas en el ámbito de la continuidad intelectual europea desde el punto de vista metodológico, Bennabī

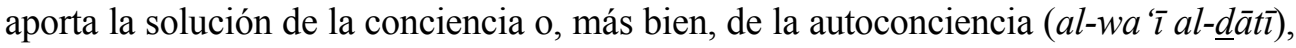
como harán también otros autores magrebíes posteriores ${ }^{30}$, para romper definitivamente

${ }^{27}$ BENNABI, Malek. Les conditions de la Renaissance..., 92. Las ideas de humanidad (al-insān), territorio (al-turāb) y tiempo (al-waqt) son claves para el concepto de «nación » desarrollado por

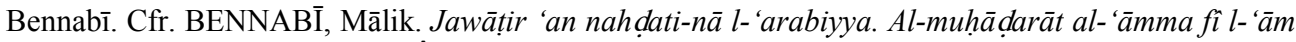
al-ŷāmi ‘̂̀ 1958-1959. Damasco: Ŷāmi‘a Dimašq, 1959, 26.

${ }^{28}$ BENNABĪ, Mālik. Šurūtal-nah da..., 157.

${ }^{29}$ Op. cit, 159.

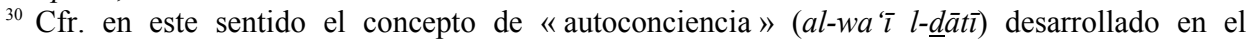
personalismo musulmán del filósofo marroquí LAḤBĀB̄̄, Muhammad 'Azīz (1923-1993). AlŠajṣāniyya al-islāmiyya. 2a ed. El Cairo: Dār al-ma‘ārif, 1983. 
con el estado de "colonizado/colonizable" y alcanzar el de "consciente" y "libre", identificado como un "progreso" en su terminología. Dado que dicho estado no se ha alcanzado aún, Bennabī observa de manera analítica la realidad árabe e islámica para detectar cuáles son los obstáculos principales que han impedido a los árabes llegar a la ansiada etapa de la nahda. Entre ellos, de los observados por el autor en el periodo 1868-1905, tres serían los principales, aún vigentes ${ }^{31}$ :

a) Falta de una clara identificación del objetivo último de la nahda;

b) Falta de una correcta identificación de los problemas sociales;

c) Falta de concreción de los medios adecuados y de sus posibilidades conforme al objetivo perseguido ${ }^{32}$.

Estos obstáculos, analizados por Bennabī casi diez años después de la aparición de Les conditions de la Renaissance, inciden en la dicotomía mencionada, no sólo entre reflexión y acción ("medios adecuados"), sino entre la linealidad del "progreso" que lleva irremediablemente a la nahda ("objetivo último"), y el desarrollo cíclico de las civilizaciones, incluidas sus sociedades y sus respectivas culturas.

En otras palabras, existe en este desarrollo intelectual una evidente tensión entre las "modernidades" a las que el autor pertenece, entre el pensamiento fenomenológico de clara raíz francesa y la búsqueda de un pensamiento neo-jalduniano y salafí endógeno que dé carta de naturaleza intelectual al pensamiento nacionalista árabe y argelino. Esta tensión, que es a la vez un elemento de originalidad y un obstáculo en la comprensión integral del pensamiento de Bennabī como una unidad, y que está presente también en algunos de sus contemporáneos, no queda finalmente superada, lo que da lugar a múltiples posibilidades de lectura de su pensamiento.

\section{B) EL FENÓMENO ISLÁMICO COMO ELEMENTO POLÍTICO ANTICOLONIAL}

El elemento islámico también juega un papel importante en este sentido, siendo probablemente uno de los elementos más destacados en las lecturas contemporáneas de su pensamiento ${ }^{33}$. La fenomenología, en este caso, sirve a Bennabī para elaborar

${ }^{31}$ Con algunas excepciones, como el papel histórico que asigna Bennabī a la Revolución de los Oficiales Libres en Egipto en 1952, la cual es considerada como un importante paso adelante del proceso de resurgimiento de la umma árabe, tanto en el ámbito cultural como, específicamente, en el político. Cfr. BENNABĪ, Mālik. Jawātị 'an nahḍati-nā..., 26.

${ }^{32}$ Op. cit, 13.

${ }^{33}$ En las últimas décadas, la prestigiosa editorial siria Dār al-Fikr ha reditado un buen número de obras de Mālik Bennabī, especialmente aquellas que tienen un mayor contenido político desde una óptica panislámica y que pueden ser releídas a la luz de los acontecimientos políticos actuales. Esto reafirma la vigencia y la influencia social del pensamiento de Bennabī a la vez que incide en la posibilidad de lecturas múltiples a la luz del contexto histórico y político poscolonial. Cfr., entre otras: BENNABĪ, Mālik. Fikrat kumunwīlt islāmī. Damasco: Dār al-fikr, 2001; Waŷh al-'ālam al- islāmī. Damasco: Dār al-fikr, 2000. 
un pensamiento crítico con respecto a la exégesis coránica clásica que incida, a su vez, en el "despertar" moral y, en última instancia, material, cultural y político de los musulmanes ${ }^{34}$. Emprendiendo una reforma (iṣlāh) de la exégesis clásica, Bennabī pretende desarrollar un método analítico en el estudio del fenómeno coránico que lleve a lo que él mismo denomina el "renacimiento musulmán" y que consiste en una renovación del ámbito espiritual y moral de los musulmanes que acompañe a los avances técnicos y políticos, en una clara adscripción salafí:

Es necesario darse cuenta, en efecto, de que en Argelia, como en todos los países árabes, la evolución cultural pasa por una fase crítica: "el renacimiento musulmán" recibe todas sus ideas técnicas de la cultura occidental, sobre todo por la vía del Egipto evolucionado (...). Estas ideas no sólo atañen a la vida material, nueva, sino también, de una manera menos perceptible, es cierto, a las cosas del espíritu, del alma. ${ }^{35}$

Desde el punto de vista político, la referencia a la ética islámica como parte del resurgimiento identitario árabe y musulmán se inscribe en el análisis de la reforma salafí del campo religioso, sosteniendo nuevamente una metafísica de la acción o, cuando menos, estableciendo un marco metafísico de desarrollo ideológico destinado a influir, en última instancia, en el campo de la acción política. El "fenómeno" religioso, por tanto, sería no sólo un sistema metafísico, sino también un sistema físico ${ }^{36}$.

Bennabī examina las fuentes de la revelación, con especial atención al Corán por encima de la sunna profética, y trata de analizarlas utilizando un criterio fenomenológico, por una parte, y un criterio racional, por otra. De esta forma, pretende aproximar el Corán a los musulmanes haciendo una exégesis receptiva y comprensible para sus contemporáneos. Así, de entre los muchos aspectos analizados en su fenomenología coránica, tales como los jurídicos, históricos, literarios, etc., pueden destacarse asimismo los elementos políticos, destinados, en última instancia, a reforzar el ámbito moral e identitario, léase cultural, aportado por el Corán a la civilización islámica. El caudal aportado por dicha lectura fenomenológica debe tener un reflejo en el resurgimiento no sólo espiritual de los musulmanes, sino también, de manera destacada, en su acceso definitivo a la modernidad material plena, incluido el ámbito político:

Un congreso islámico deberá emprender una verdadera planificación del problema musulmán a partir de la base, con objeto de hacer pasar a quinientos millones de hombres de un estado de pre-civilización al estado de civilización, y de hacerlo en un tiempo dado, utilizando eficazmente los medios espirituales y materiales de estas multitudes humanas. ${ }^{37}$

${ }^{34}$ BENNABI, Malek. Le phénomène coranique. Essai d'une théorie sur le Coran. Argel: Ennahda, 1946.

${ }^{35}$ Op. cit, 9.

${ }^{36}$ Op. cit, 21.

${ }^{37}$ BENNABI, Malek. L'Afro-asiatisme. Conclusions sur la conférence de Bandoeng. El Cairo: Imprimerie Misr, 1956, 308-309. 
Se trata por tanto de acceder a la revelación coránica y a la vida espiritual no desde una cómoda posición individual e individualista, sino desde una plena autoconciencia de humanidad que relacione al individuo musulmán con la colectividad a la que pertenece, es decir, con el resto de la umma islámica, identificándose plenamente con sus problemas y anhelos, y ligándose de manera definitiva a su progreso y a su devenir cultural, social y político ${ }^{38}$. Es lo que Bennabī denomina un "islam social". En otras palabras, para Bennabī no es posible abordar el proceso de toma de conciencia de sí mismos, de resurgimiento y de liberación anticolonial sin tener en cuenta la dimensión espiritual colectiva que, nuevamente, debe ser sostenida y argumentada en el plano metafísico por la referencia a la revelación islámica, con especial atención a su corpus axiológico:

La fuerza de cohesión necesaria para la sociedad argelina está eminentemente en el islam, pero en un islam repensado y revisado, en un islam social (islām iŷtima $\left.{ }^{\mathfrak{\imath}} \vec{\imath}\right){ }^{39}$

A partir del desarrollo de dicha relación colectiva que parte de una relectura moral de las fuentes de la revelación y que está marcada por la denominada "fuerza de cohesión", claramente identificable con la 'aṣabiyya jalduniana, Bennabī plantea como siguiente paso abordar cuestiones fundamentales del ámbito metafísico para mejorar el plano material (socio-político) de los musulmanes, las cuales constituyen verdaderos núcleos duros del eje reflexión-acción de su pensamiento. Entre dichas cuestiones: "¿Qué hace falta transformar en el alma musulmana para eliminar el "mal" del mundo musulmán? ¿Cuáles son los medios y los métodos de esta transformación? ¿Cuál es el objetivo o la causa final que vislumbre dicha transformación?" " Algunas de estas cuestiones, por otra parte, permanecen aún vigentes en el pensamiento islámico contemporáneo.

\section{LA NAHDA Y EL DESPERTAR POLÍTICO AFRO-ASIÁTICO}

Uno de los momentos culminantes para el desarrollo del pensamiento político de Mālik Bennabī fue la celebración de la Conferencia de Bandung ${ }^{41}$. En ella, Bennabī

${ }^{38}$ Op. cit, 316.

${ }^{39}$ BENNAB̄̄, Mālik. Šurūtal-nah đa..., 99.

${ }^{40}$ BENNABI, Malek. L'Afro-asiatisme..., 321.

${ }^{41}$ La Conferencia de Bandung, que tuvo lugar entre el 18 y el 24 de abril de 1955, supuso el primer intento de afrontar el problema del colonialismo y el poscolonialismo desde la perspectiva de los países recién independizados, o en vías de hacerlo, de Asia y África mediante la cooperación mutua y la neutralidad. Con ella dio comienzo el movimiento de los países no-alineados. La importancia de dicha conferencia en el Magreb pre y post-independiente dejaría influyentes testimonios ideológicos y políticos, tales como los del propio Bennabī en Argelia o el del malogrado Mahdī Ben Barka (19201963) en Marruecos. Cfr. ŶAMALĪ, Muhammad Fāḍil al-. "Al-Magrib al-'arabī wa-mu’tamar 
concibió una nueva esperanza de desarrollo social y político para Argelia y otros pueblos colonizados o recién independizados de África y Asia, principalmente, y encontró un foro adecuado para desarrollar su pensamiento político anticolonial nacionalista e islámico. Dichas ideas son plasmadas por Bennabī en su obra sobre el llamado "afro-asiatismo", que titula de igual forma ${ }^{42}$. En ella, en continuidad con el pensamiento desarrollado en Šurūt al-nahḍa, Bennabī se sitúa en una posición política nacionalista activa de inclinación naserista ${ }^{43}$, lo que le lleva a reafirmarse metodológicamente en la linealidad histórica de su pensamiento, decididamente moderno:

La idea afro-asiática es una de esas posiciones que la historia no abandonará. Ella marca para una parte de la humanidad una nueva base de partida hacia el cumplimiento de su destino. ${ }^{44}$

Nuevamente, la noción de "destino" evoca la linealidad de una historia que aparentemente no tiene vuelta atrás. En dicho proceso de recuperación de la autoconciencia, de toma de posición en el mundo previo al acceso pleno a la modernidad y a la libertad mediante la nahda, sigue siendo importante, por una parte, la reafirmación de la propia identidad (cultural, civilizacional) frente al colonizador; por otra, es importante actuar en la historia para que los pueblos colonizados puedan cambiar los parámetros históricos y políticos vigentes. En ambos procesos (autoconciencia y acción), Bennabī señala la Conferencia de Bandung como un punto culminante, como un momento crucial de la historia, dado que permitió operar el comienzo del cambio de "la técnica por la ética, el advenimiento de lo humano sobre lo político" ${ }^{45}$. $\mathrm{O}$, en otras palabras, supuso una experiencia histórica para el devenir del colonialismo y el inicio de la toma de conciencia afro-asiática al ser una "creadora de existencia" del colonizado ${ }^{46}$.

Desde unos parámetros de análisis histórico-políticos, Bennabī describe la situación de postración del "hombre afro-asiático" como imagen de un pueblo sometido a una minoría y convertido en tributario de los que llama los "grandes"

Bāndūng”. Al-Maŷalla al-Tārījiyya al-Magāribiyya, 2 (1974), 118-124; y GALLISOT, René. Après Bandoeng, du Caire et d'Alger à La Havane: Ben Barka et la Tricontinentale. París: Syllepse, 2007.

${ }^{42} \mathrm{La}$ mencionada obra de Mālik Bennabī L'Afro-asiatisme. Conclusions sur la conférence de Bandoeng, de 1956, fue escrita primero en francés, al igual que el resto de sus obras principales, apareciendo en árabe unos años después. Cfr. BENNABĪ, Mālik. Al-Afrū-asiyāwiyya. El Cairo: s.e. 1960. La versión árabe utilizada en el presente artículo es una edición posterior: BENNABĪ, Mālik. Fikrat al-afrīqiyya al-asiyāwiyya. Fū ḍaw' mu'tamar Bāndūnŷ. Damasco: Dār al-fikr, 1981.

${ }^{43}$ Desde el comienzo de la obra puede verse dicha línea ideológica, puesto que contiene una dedicatoria laudatoria al entonces presidente egipcio Ŷamāl 'Abd al-Nāṣir (1918-1970) en los siguientes términos: "Al hombre en quien se encarna una doble revolución: la revolución política que ha dado a Egipto la República, y la revolución psicológica que marca, en el mundo musulmán, el advenimiento de la dirección técnica". BENNABI, Malek. L'Afro-asiatisme... s.p.

${ }^{44}$ Op. cit, 19.

${ }^{45}$ Op. cit, 12-13.

${ }^{46}$ Op. cit, 105. 
(al-kibār), es decir, las potencias colonizadoras, en la dirección de sus propios asuntos, sobre los que los "indígenas" no tienen ningún poder de decisión. Esta situación está sostenida por un orden moral injusto, según Bennabī, dado que "los grandes" lo son en virtud de sus capacidades técnicas y económicas, pero no en virtud de su altura moral o humana:

Desafortunadamente, toda la vida internacional está dominada por la "voluntad de poder" que es inseparable de la civilización del siglo XX. Es una norma de la psicología occidental, que marca el retraso moral del hombre de occidente como si aún viviera en el siglo XIX. ${ }^{47}$

Dicha "voluntad de poder" de occidente reafirma, para Bennabī, una doble condición, hasta cierto punto paradójica, del contexto histórico y político de la descolonización: por una parte, la civilización occidental estaría en un estado de decadencia (al-garìza o "estado primitivo" en la concepción cíclica de Bennabī); por otra, la civilización árabe e islámica, englobada en el movimiento de los noalineados afro-asiáticos, estaría desarrollando los medios éticos y técnicos, mediante análisis como el del propio Bennabī, para alcanzar su estado máximo de desarrollo ( $a q l$ o "razón"). En el ínterin, es la civilización occidental colonizadora la que impone sus reglas en los dominios "materiales". Sin embargo, apoyado en la linealidad de la historia, Bennabī considera que esta situación contraviene el "decurso histórico" que, paradójicamente, es acelerado por el propio desarrollo técnico de occidente. La dialéctica entre el campo moral, metafísico, y el de la técnica, físico, es la que en última instancia mantiene esta situación, al mismo tiempo que contiene los elementos para su resolución. La ecuación, un tanto simplista pero clarificadora, desarrollada por Bennabī consiste en la argumentación de que la civilización occidental tiene la técnica pero no la moral, mientras que la civilización árabe e islámica tiene la moral pero carece de técnica: Bennabī sostiene que cuando esta última consiga la técnica, logrará emanciparse y dejar de ser "colonizable" (nahda). Sin embargo, en ningún momento plantea la posibilidad de que, al igual que ha ocurrido con la civilización occidental, la adquisición de los medios técnicos suponga la pérdida de la moral. Es decir que, en cierto sentido, el desarrollo cíclico de las civilizaciones se acabaría definitivamente con la nahḍ que, en ese caso, supondría un destino histórico definitivo.

Así, para Bennabī el factor técnico es un factor de homogeneidad y unidad que dota a los pueblos desarrollados de un "destino privilegiado", imponiendo a la humanidad un destino colectivo, cierto determinismo unificador. Frente a ello, Bennabī considera que es imprescindible abordar el "problema humano" desde la

\footnotetext{
${ }^{47}$ Op. cit, 28.
} 
diversidad, pero también desde la unidad de las aspiraciones colectivas de los pueblos afro-asiáticos ${ }^{48}$.

La solución no puede ser otra que la toma de conciencia frente al colonizador y el acceso definitivo a la nahda como "renacimiento", que debe ser abordada, por tanto, desde la unidad y la diversidad. Es decir, debe abordar el resurgimiento de los elementos éticos y estéticos del propio ser árabe y musulmán, especialmente en el ámbito de lo cultural y lo social, además de desde su propia experiencia histórica y vital, sin por ello rechazar todo lo que proviene del desarrollo de la civilización occidental, tomando los elementos que resulten útiles y positivos para el desarrollo, especialmente en el campo de la técnica. De ahí que, al igual que a la hora de abordar las "orientaciones" de la nahḍa, Bennabī tampoco quiera marcar un proyecto pormenorizado a priori:

La nahḍ musulmana en sus medios culturales, allí donde se manifiestan más claramente su pensamiento y su esfuerzo, no da la impresión de ser neta, clara, de tener un modelo escogido. Se diría que se desarrolla sobre la influencia de un modelo oculto que no se ha escogido y se ha impuesto a sí mismo a gusto de la gente, como para evitarles el esfuerzo de pensar una alternativa. Se siente vagamente, en un examen sumario, que el "renacimiento" musulmán tiene por maestro a occidente (...). En particular, el mundo musulmán no puede ni debe seguir todos los trazos del largo camino que occidente ha seguido. No le hace falta diseñar un patrón tan rápido. No se trata de imitar una evolución, sino de resumirla en lo que tiene de esencial y universal. ${ }^{49}$

Entre los elementos de diversidad, Bennabī habla abiertamente de la relación entre deber y derecho para afirmar la diversidad metodológica entre el colonizador y los pueblos afro-asiáticos. Así, mientras que para el colonizador, carente de moral, todos los medios son válidos para lograr sus objetivos, imponiendo el deber sobre el derecho, para los pueblos en vías de emancipación la no violencia y el deber del derecho son las características que deben regular su comportamiento político.

Por tanto, y a pesar de la falta de concreción del proyecto, también la metodología de la nahda debe basarse en los principios de orden moral destacados una y otra vez por Bennabī, quien encuentra en el islam el marco de ordenación fundamental de los valores morales fundamentales, como se ha visto. Por ello la "solución" afro-asiática es considerada por Bennabī como clarificadora y decisiva, al poder aunar los esfuerzos colectivos de los pueblos colonizados, como una unidad en la diversidad, revalorizando y redescubriendo sus propios valores y riquezas culturales.

Desde un punto de vista más pragmático, Bennabī también considera que, además de la cultura, la economía y la política son beneficiadas por la idea afroasiática. Así, y a pesar de la falta de concreción a la hora de tratar estos aspectos

\footnotetext{
${ }^{48}$ BENNABĪ, Mālik. Fikrat al-afrīqiyya ..., 75.

${ }^{49}$ BENNABI, Malek. L'Afro-asiatisme..., 93-94.
} 
característica de Bennabī, éste considera que la economía a desarrollar no debe ser una economía de tipo marxista, puesto que para él tiene más importancia el hecho social que el hecho material, sino que debe estar basada en la recuperación de las industrias y los medios propios mediante una participación eficaz en los mismos. Una economía, en todo caso, sustentada en la cultura y la política.

El dominio de la política será también el que deba predominar, según la idea de Bennabī, en las relaciones internacionales entre países emancipados, sin que exista "co-colonización" sino coexistencia basada en una cooperación eficaz. De hecho, considera que la coexistencia (al-ta 'āyiš) "es el ethos del afro-asiatismo" ${ }^{50}$ y que, además de garantizar una coexistencia pacífica, ésta debe redundar en la igualdad de derechos y de beneficios mutuos, saliendo definitivamente de la dinámica de bloques y del enfrentamiento que caracterizaba la época colonial e imperialista, dentro de lo que define como una "vocación de universalidad humana" ${ }^{1}$ que relaciona de forma general con la idea del sistema cooperativo de gobierno mundial de Toynbee ${ }^{52}$. Nuevamente, el pensamiento de Bennabī se descubre como continuador, quizás a su pesar, del pensamiento europeo en lo que concierne al desarrollo de una teoría de las relaciones internacionales. Es evidente que la conceptuación de Bennabī pierde originalidad cuando se aproxima al ámbito del derecho, en el que el espacio de su reflexión queda irremediablemente reducido. La dialéctica entre lo universal, la vocación a la que está llamada el afro-asiatismo y la nahda, en último término, y las particularidades del ser afro-asiático, y específicamente del árabe-islámico, constituye uno de los ejes principales del pensamiento político de Bennabī, si bien al mismo tiempo la paradoja entre la linealidad histórica y el desarrollo cíclico de las civilizaciones sigue siendo un elemento de distorsión del mismo, resuelto en última instancia mediante el deus ex machina del derecho y el destino universal, en el que la dialéctica entre técnica y moral juega un papel dinamizador, pero no definitivo.

Todo ello, no obstante, no redunda en la falta de altura del pensamiento político de Bennabī, que, analizado en el contexto de la descolonización argelina, supone una de las aportaciones fundamentales del pensamiento magrebí. Las tensiones entre el ser y el estar, en todo caso, que se encuentran en la propia persona de Bennabī y en su obra, sin que lleguen nunca a ser superadas, son características de un pensamiento con vocación activa y movilizadora y no constituyen un déficit del mismo.

De hecho, en el primer libro que Bennabī escribe directa y personalmente en árabe, al-Şirā' al-fikrī fì l-bilād al-musta 'mara, de 1960" como la colonización y el proceso histórico y dialéctico de la descolonización han

${ }^{50}$ BENNABĪ, Mālik. Fikrat al-afrīqiyya ..., 171.

${ }^{51}$ BENNABI, Malek. L'Afro-asiatisme..., 242.

${ }^{52}$ BENNABĪ, Mālik. Fikrat al-afrīqiyya..., 193.

${ }^{53}$ BENNABĪ, Mālik. Al-Sirā' al-fikrī fì l-bilād al-musta 'mara. El Cairo: Dār al-‘urūba, 1960. La editorial Dār al-Fikr reeditó también esta obra en Damasco en 2001. 
hecho necesaria una profunda reflexión teórica en busca de ideas con las que "enfrentarse" al colonizador en el terreno intelectual y entender los medios de la colonización en la lucha intelectual. A partir de dicha reflexión, Bennabī extrae una valiosa conclusión: la consideración de colonizados es la clave para entender la realidad árabe y musulmana y responder dialécticamente a la colonización. Ésta, por su parte, responde a través de la psicología y de la lucha ideológica, intentando que los colonizados se dividan en diferentes tendencias y rompiendo de esta manera su unidad. La idea de la colonización (fikrat al-musta 'amara), según Bennabī, ha sido inoculada tan profundamente en las sociedades colonizadas que ni siquiera sus intelectuales más críticos y progresistas son a veces capaces de ser conscientes del estado de colonizado en el que se encuentran, constituyendo uno de los mayores peligros para emprender el proceso de renacimiento. Esta idea, que constituye uno de los ejes fundamentales del backlash colonialista, sigue en gran medida vigente en las sociedades poscoloniales, de ahí la importancia que da Bennabī al posicionamiento ideológico del intelectual, es decir, a la conciencia de ser y actuar como colonizado. De otra manera, sin esta consciencia sería imposible desarrollar un pensamiento político válido para las sociedades de las que surge (sujeto) y a las que se dirige (objeto), en este caso las sociedades árabes y musulmanas.

El pensamiento de Bennabī en términos generales y el concepto de "nahḍa" en particular pretenden aunar los esfuerzos de intelectuales y pensadores en aras de la unidad de pensamiento en tanto colonizados, a pesar de la diversidad de actitudes y posturas políticas. Ése es el mayor valor de la aportación intelectual de Mālik Bennabī al pensamiento político árabe y magrebí.

\section{CONCLUSIÓN}

Tras el análisis emprendido del concepto de "nahḍa" en el pensamiento político de Mālik Bennabī, puede afirmarse que, en términos generales, dicho pensamiento está fundamentado, atravesado y circunvalado por múltiples dimensiones que se engarzan y se superponen, tanto desde el punto de vista epistemológico como desde el metodológico. En primer término, en términos epistemológicos, existe una dimensión cultural fundamental y una dimensión política que la completa. En términos metodológicos, existe una dimensión fenomenológica, en ciertos momentos estructuralista, y otra dimensión salafí con elementos neo-jaldunianos. En todas ellas, lo particular y lo universal, como la unidad y la diversidad, se encuentran relacionados dialécticamente, sin que en la mayoría de ocasiones pueda entenderse lo uno sin lo otro.

En este sentido, el concepto de "nahḍa" supone un hilo conductor del pensamiento de Bennabī, constituyendo probablemente el vector fundamental de análisis de su obra. La nahda, como concepto, es por tanto cultural y política, así 
como un fenómeno espiritual-moral del ámbito islámico pero también de alcance material que se opone al materialismo del colonizador. La nahḍ es también única en sus aspiraciones de emancipación y libertad, y diversa en sus aportaciones culturales y técnicas, así como en su método. Es asimismo el nexo de unión de la historia, entendida como un desarrollo lineal del tiempo, con la concepción cíclica del desarrollo de las civilizaciones, constituyendo el punto culminante y sin retorno al que aspiran las sociedades colonizadas afro-asiáticas y particularmente las árabes y musulmanas. Finalmente, la nahda es un producto de la reflexión intelectual e incluso de la crítica exegética de la revelación islámica en un marco socio-histórico determinado, así como una propuesta y un marco de acción política anti-colonial.

Todos los elementos citados sirven a Bennabī para elaborar un pensamiento político dinámico, cuyos principales valores son el fundamento de su reflexión intelectual, basada en la completa consciencia ideológica de ser colonizado, y la aspiración movilizadora de elaborar un pensamiento activo y útil. Ese mismo pragmatismo, por lo dinámico, deja abiertas las puertas del análisis técnico y metodológico, aspecto en el que se concretan las mayores tensiones de su pensamiento. Tensiones que, como se ha dicho, son producto de su propia experiencia vital y que, por tanto, deben ser tenidas en consideración en cuanto tales, y no minusvaloradas como un déficit teórico: la amplia influencia que aún hoy tiene su reflexión ideológica en las sociedades magrebíes, también inmersas en tensiones culturales y políticas, y la vigencia de sus proposiciones teóricas en el contexto neocolonialista y a la luz de los recientes acontecimientos acaecidos en el mundo árabe, así lo aconsejan. 